\title{
Crack-Healing Behavior and Mechanical Strength Recovery of 5 vol\% Silicon Carbide Particle Dispersed Yttrium Monosilicate Composites
}

\author{
Huy D. $\mathrm{Vu}^{1}$ and Makoto Nanko ${ }^{2, *}$ \\ ${ }^{1}$ Graduate School of Engineering, Nagaoka University of Technology, Nagaoka 940-2188, Japan \\ ${ }^{2}$ Department of Mechanical Engineering, Nagaoka University of Technology, Nagaoka 940-2188, Japan
}

\begin{abstract}
Crack-healing effectiveness was investigated as functions of heat treatment time and temperature on 5 vol\% $\mathrm{SiC}_{\text {-dispersed }} \mathrm{Y}_{2} \mathrm{SiO}_{5}$-based composites. Dense specimens of $\mathrm{SiC} / \mathrm{Y}_{2} \mathrm{SiO}_{5}$ composite were fabricated by the pulsed current sintering technique. Thermal oxidation for crackhealing was conducted at temperatures ranging from 1000 to $1300^{\circ} \mathrm{C}$ for from 1 to $24 \mathrm{~h}$ in air. Bending tests were carried out at room temperature on samples before and after heat treatment in order to clarify the crack-healing performance. The results show that $\mathrm{SiC} / \mathrm{Y}_{2} \mathrm{SiO}_{5}$ composites possess a considerable crack-healing ability. The surface cracks with approximately $200 \mu \mathrm{m}$ in length introduced on the sample surface were disappeared completely after heat treatment at $1300^{\circ} \mathrm{C}$ for $1 \mathrm{~h}$ in air. Mechanism of crack-healing was considered as filling up of cracks by $\mathrm{Y}_{2} \mathrm{Si}_{2} \mathrm{O}_{7}$ oxidation product which is formed by outward diffusion of cations. Bending strength of samples introduced surface cracks after heat treatment was recovered up to the level as high as that of as-sintered samples. [doi:10.2320/matertrans.M2018193]
\end{abstract}

(Received June 11, 2018; Accepted October 26, 2018; Published December 7, 2018)

Keywords: self-healing, high-temperature oxidation, ceramic matrix composites, silicon carbide, yttrium monosilicate

\section{Introduction}

Improving thermal efficiency and reducing $\mathrm{CO}_{2}$ emission are the main driving force for increasing gas turbine engine inlet temperatures. In order to achieve higher operation temperatures of gas turbine engines, developments of hightemperature materials have been one of major factors. Currently, the turbine engines are constructed of metallic alloys such as nickel-based superalloys, which operated within strict temperature limits. Ceramic materials are considered as potential materials to extend these temperature limits because of their high melting points and chemical stability at high temperatures. One promising candidate attracted wide attention and developed to replace metallic alloys is silicon-based ceramics like $\mathrm{SiC}$ and $\mathrm{Si}_{3} \mathrm{~N}_{4} \cdot{ }^{1)}$ These ceramic materials exhibit excellent oxidation resistance in dry and clean air by forming a protective silica scale. ${ }^{2)}$ However, when Si-based ceramics are exposed to combustion environments containing high-pressure steam at elevated temperatures, the protective silica scale reacts with water vapor, forming gaseous reaction products such as $\mathrm{Si}(\mathrm{OH})_{4}{ }^{3)}$ In order to extend their service time, protection of these ceramic materials from water vapor corrosion by application of external environmental barrier coatings (EBCs) is essentially necessary.

Mullite attracted the most interest as a protective coating for $\mathrm{SiC}$ and $\mathrm{Si}_{3} \mathrm{~N}_{4}$ ceramics in the early days of coating development due to its low thermal expansion coefficient, and chemical compatibility with Si-based ceramics. ${ }^{4,5)}$ One major issue with plasma-sprayed mullite coating is the phase stability. ${ }^{5)}$ In process of conventional plasma-sprayed mullite, considerable amount of amorphous phase mullite was appeared due to the rapid cooling of molten mullite during its solidification on a cold substrate. The crystallization of the amorphous phase under thermal cycling, which accompanies a volumetric contraction, causes cracking and delamination

*Corresponding author, E-mail: nanko@mech.nagaokaut.ac.jp of the mullite coating. In order to eliminate most of the amorphous phase mullite from the coating, plasma spraying was carried out while heating the $\mathrm{SiC}$ substrate above the crystallization temperature of amorphous mullite. ${ }^{5)}$ Another key issue of the mullite coating is the relatively high silica activity and the resulting recession in high velocity combustion environments due to the volatilization of silica by water vapor. ${ }^{6}$ ) To overcome the recession of mullite, a water vapor resistant coat was added on top of mullite coating. Consequently, the first generation EBC was developed by adding YSZ $\left(\mathrm{ZrO}_{2}-8\right.$ mass $\left.\% \mathrm{Y}_{2} \mathrm{O}_{3}\right)$ top coat. $\left.{ }^{6}\right)$ These first-generation EBCs provided protection from water vapor for a few hundred hours at $1300^{\circ} \mathrm{C}$. In longer exposures under thermal cycling, the coefficient of thermal expansion (CTE) mismatch of YSZ and mullite causes severe cracking and delamination.

As the second generation EBCs, barium strontium aluminum silicate (BSAS) has already been applied successfully on hot sections of turbine engines. ${ }^{7,8)}$ The YSZ top coat was replaced with BSAS which exhibited excellent crack resistant due to reduce tensile stress resulting from the low CTE of BSAS. However, the BSAS has durability issues that limit their service temperatures and lifetime. One is the chemical reaction with silica, which formed on $\mathrm{Si}$ bond coat by oxidation at high temperature, to form a low melting glass $\left(\sim 1300^{\circ} \mathrm{C}\right)$ that causes $\mathrm{EBC}$ degradation and failure at temperatures above $1300^{\circ} \mathrm{C}$. $^{8)}$ The other is the volatilization of the BSAS coatings in high velocity combustion environments. ${ }^{9)}$

In recent years, in order to develop new EBCs that can withstand higher temperatures in longer exposure time, rare earth silicates have been studied as new EBC materials because of their outstanding durability at high temperatures, excellent chemical compatibility with silicon-based ceramics, and good water vapor corrosion resistance. Among those rare earth silicates, yttrium silicates, including yttrium monosilicate $\left(\mathrm{Y}_{2} \mathrm{SiO}_{5}\right)$ and yttrium disilicate $\left(\mathrm{Y}_{2} \mathrm{Si}_{2} \mathrm{O}_{7}\right)$, are promising candidates. Because they display low coefficients 
of thermal expansion, $3.9 \times 10^{-6} \mathrm{~K}^{-1}$ for $\mathrm{Y}_{2} \mathrm{Si}_{2} \mathrm{O}_{7}$ and $5.4 \times$ $10^{-6} \mathrm{~K}^{-1}$ for $\mathrm{Y}_{2} \mathrm{SiO}_{5}$, which are close to that of $\mathrm{SiC}$, as well as low oxygen permeability.

However, application of these ceramics must face a challenge on their brittle property. If the EBCs are fractured to expose the substrate, EBCs will no longer protect the substrate from high temperature steam oxidation. Selfhealing function of ceramic based composites could be excellent solutions for EBC layers. Crack-healing function was discovered on some ceramic matrix composites dispersed with non-oxide phases by Ando et al. ${ }^{10)}$ Nonoxide phases dispersed in ceramics matrix were oxidized within surface cracks by heat treatment, resulting in oxidation products filling the cracks. As a result, stress concentration at the crack tip was decreased and lead to recovery of the fracture strength. SiC particles or whiskers dispersoid were typically used for crack-healing function in ceramic matrix composites. Ando and his co-workers reported about the crack-healing ability of $20 \mathrm{vol} \% \mathrm{SiC}$ particles dispersed in mullite matrix. ${ }^{11)}$ The specimens introduced surface cracks with approximately $200 \mu \mathrm{m}$ in length were heat treated in air at temperature ranging from 1000 to $1300^{\circ} \mathrm{C}$ for from 1 to $20 \mathrm{~h}$. The cracking decreased the bending strength of sample to approximately $140 \mathrm{MPa}$. However, after heat treatment at $1300^{\circ} \mathrm{C}$ for $1 \mathrm{~h}$, the cracks were disappeared completely. The bending strength of as-healed sample significantly increased to up to $520 \mathrm{MPa}$ comparable with that of as-sintered sample. The crack-healing function of $\mathrm{Al}_{2} \mathrm{O}_{3}$ matrix composites dispersed with $20 \mathrm{vol} \% \mathrm{SiC}$ whiskers was investigated by Takahashi et al. ${ }^{12)}$ Specimens for crack-healing test as well as bending test were prepared by introducing cracks on the surface and heat treatment at from 1000 to $1300^{\circ} \mathrm{C}$ for $1 \mathrm{~h}$ in air. The bending strength of specimens heat-treated at 1200 and $1300^{\circ} \mathrm{C}$ for $1 \mathrm{~h}$ in air are 970 and $980 \mathrm{MPa}$ similar to that of as-sintered sample, respectively, while the bending strength of as-cracked sample was $440 \mathrm{MPa}$. The surface cracks with length of $100 \mu \mathrm{m}$ can be healed completely at 1200 or $1300^{\circ} \mathrm{C}$ for $1 \mathrm{~h}$ in air. The cracks were healed by filling with oxidation product of $\mathrm{SiO}_{2}$.

Additionally, self-healing function on thermal barrier coatings (TBCs) was reported previously. ${ }^{13-16)}$ In order to improve thermal efficiency and performance of gas turbine engines, mainly through the increase in inlet temperature above the melting temperature range of nickel-based superalloys as well as through the reduction of the requirements for cooling system, high temperature protective ceramic coatings, known as thermal barrier coatings, were developed. ${ }^{17)}$ However, the CTE mismatch between the metal substrate and the ceramic TBCs may results in development of micro-cracks in the TBCs. This damage leads to failure of the top coat and reduce life time of the coating systems. ${ }^{18,19)}$ Therefore, it has been proposed to embed healing agents inside the top coat of the coating system. The healing agents were oxidized at high temperature in air to generate oxidation products and fill in the cracks. The healing function causes effective disappearance of the cracks. The self-healing ability of the TBCs extends its life time and enhances its reliability.

We have proposed the self-healing ceramic composites which will be applied for EBC systems. ${ }^{20)}$ Crack-healing ability induced by thermal oxidation has been investigated for
$\mathrm{SiC}$ particles in $\mathrm{Y}_{2} \mathrm{SiO}_{5}$ matrix. Although a crack-healing function was discovered in $\mathrm{SiC} / \mathrm{Y}_{2} \mathrm{SiO}_{5}$, influences of heat treatment condition such as time and temperature as well as mechanism of the crack-healing have not been investigated well. Recently, crack-healing function of ytterbium silicates $\left(\mathrm{Yb}_{2} \mathrm{SiO}_{5}\right.$ and $\left.\mathrm{Yb}_{2} \mathrm{Si}_{2} \mathrm{O}_{7}\right)$ composites dispersed with $\mathrm{SiC}$ particles has been reported by Nguyen and his co-workers. ${ }^{21)}$ Surface cracks were healed after annealing at $1250^{\circ} \mathrm{C}$ in air. The authors mention that the crack-healing occurred by volume expansion on high temperature oxidation of $\mathrm{SiC}$ particles into $\mathrm{Yb}_{2} \mathrm{Si}_{2} \mathrm{O}_{7}$ with $\mathrm{Yb}_{2} \mathrm{SiO}_{5}$ matrix.

In this study, 5 vol\% $\quad \mathrm{SiC} / \mathrm{Y}_{2} \mathrm{SiO}_{5}$ composite was investigated as a self-healing composite applied for EBCs. The bulk composites were fabricated by pulsed electric current sintering (PECS) technique. The crack-healing function induced by high-temperature oxidation was investigated at temperature ranging from 1000 to $1300^{\circ} \mathrm{C}$ for from 1 to $24 \mathrm{~h}$ in air. Bending tests were carried out at room temperature with as-sintered, as-cracked and as-healed samples in order to estimate the recovery of mechanical strength.

\section{Experimental Procedure}

The starting powders used to fabricate the composites were single-phase $\mathrm{Y}_{2} \mathrm{SiO}_{5}$ synthesized via a solid-state reaction technique $^{20)}$ and a commercial high-purity $\mathrm{SiC}$ powder $(0.32 \mu \mathrm{m}$ mean particle size, $99.9 \%$ purity, Ibiden Co., Ltd). A slurry mixture consisting of $\mathrm{Y}_{2} \mathrm{SiO}_{5}$ and $5 \mathrm{vol} \% \mathrm{SiC}$ powder was ball-milled with ethanol and alumina balls in a plastic bottle for $24 \mathrm{~h}$. The ceramic slurry was dried at $100^{\circ} \mathrm{C}$ for $10 \mathrm{~h}$ and milled manually by an alumina mortar to eliminate the agglomeration of particles. Bulk specimens of the composites were fabricated by pulsed electric current sintering with a graphite die in vacuum at $1600^{\circ} \mathrm{C}$ under $70 \mathrm{MPa}$ in uniaxial pressure for $5 \mathrm{~min}$ holding time. Density of the as-sintered sample was measured by the Archimedean method with toluene. Relative density of all the bulk specimens reached at least $99 \%$ of the theoretical value of the composites. Figure 1 shows polished surface of the assintered sample observed by the scanning electron microscope (SEM). SiC particles, which could be observed as black dots, were homogeneously dispersed in $\mathrm{Y}_{2} \mathrm{SiO}_{5}$ matrix.

The effectiveness of crack-healing was investigated by using specimens with introduced cracks on polished surface. Three Vickers indentations at a load of $20 \mathrm{~N}$ for $10 \mathrm{~s}$ were introduced to prepare 12 cracks on the sample surface. Semicircular cracks with $200 \mu \mathrm{m}$ in length and $100 \mu \mathrm{m}$ in depth were made, as shown in Fig. 2. Specimens with introduced surface cracks were heat treated at temperatures ranging from 1000 to $1300^{\circ} \mathrm{C}$ for from 1 to $24 \mathrm{~h}$ in air. Surface crack disappearance was observed by SEM. The surface crack disappearance was evaluated by basing on amount of surface crack length remaining after heat treatment as Maruoka et al. mentioned previously. ${ }^{22}$ The oxidized samples were also analyzed by using X-ray diffraction (XRD) for phase identification on the sample surface and electron probe microanalysis (EPMA) for microstructure analysis.

Specimens used for bending test were cut into a rectangular shape with $3 \times 4 \times 24 \mathrm{~mm}$ in dimensions. The 


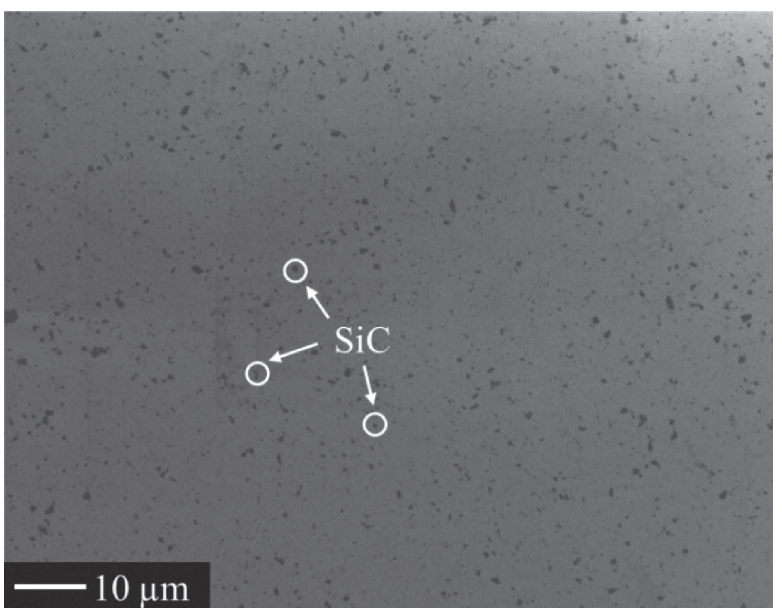

Fig. 1 SEM image of a polished surface of as-sintered sample.

mirror polished surface was prepared by using a grinding wheel with $30 \mu \mathrm{m}$-diamond grains and polishing with $2 \mu \mathrm{m}$ diamond particles slurry. Three-point bending tests were conducted with a cross-head speed of $0.5 \mathrm{~mm} / \mathrm{min}$ at room temperature. ${ }^{23)}$ After bending test, surface of bended samples was observed by SEM to determine the fracture.

\section{Results}

Figure 3 shows SEM images observed on surface of samples before and after heat treatment for $1 \mathrm{~h}$ at various oxidation temperatures. The dash lines present the outline of the Vickers indentation. Before heat treatment, the cracks on surface of sample propagated from corners of the imaged Vickers indentation could be observed obviously, as shown in Fig. 3(a). After heat treatment at $1200^{\circ} \mathrm{C}$ for $1 \mathrm{~h}$ in air, sample surface was covered with oxidation products, as presented in Fig. 3(b). Surface cracks were healed partially. The surface crack disappearance was initially observed at the end of each crack and then the disappeared area extended to the corner of the Vickers indentation. Surface cracks were disappeared completely after heat treatment at $1300^{\circ} \mathrm{C}$ for $1 \mathrm{~h}$ in air, as shown in Fig. 3(c).

Figure 4 represents the fraction of crack disappearance of specimens heat-treated in the logarithm of the reciprocal heat-treatment time as a function of the reciprocal heating
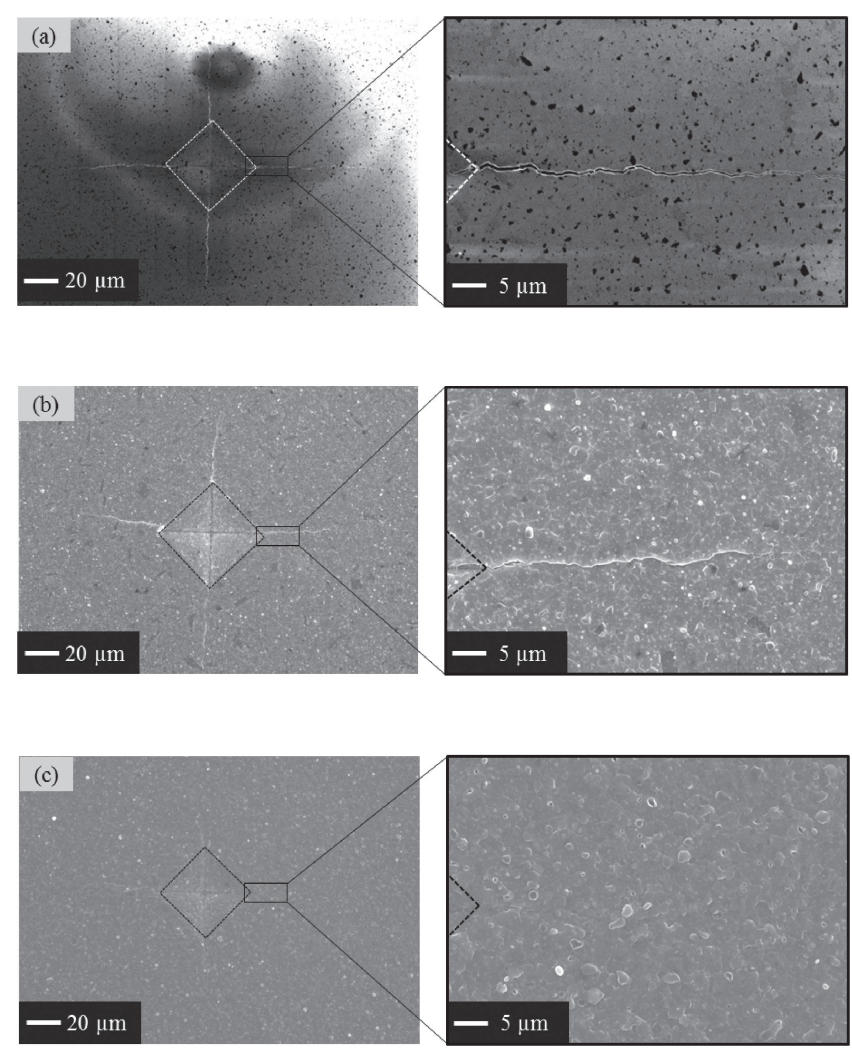

Fig. 3 SEM images of surface view of (a) as-cracked sample and samples heat-treated at (b) $1200^{\circ} \mathrm{C}$ for $1 \mathrm{~h}$ and (c) $1300^{\circ} \mathrm{C}$ for $1 \mathrm{~h}$.

temperature. Crack disappearance was categorized into three groups by less, partial and complete disappearance. This graph showed that fraction of crack disappearance was increased with increasing heat treatment temperature and time.

Figure 5 shows XRD patterns obtained from the sample surface before and after heat treatment for $1 \mathrm{~h}$ at 1000, 1200 and $1300^{\circ} \mathrm{C}$ in air. Figure 5(a) shows the results for the assintered specimen in which only $\mathrm{Y}_{2} \mathrm{SiO}_{5}$ and $\mathrm{SiC}$ peaks were detected and no other crystalline phases were observed. After oxidation at $1000^{\circ} \mathrm{C}$ for $1 \mathrm{~h}$ in air, no changes were observed on surface of sample because high-temperature oxidation did not occur. No new peaks were detected, as shown in Fig. 5(b). The XRD patterns of samples heat-treated for $1 \mathrm{~h}$ at 1200 and $1300^{\circ} \mathrm{C}$ were respectively presented in Figs. 5(c)
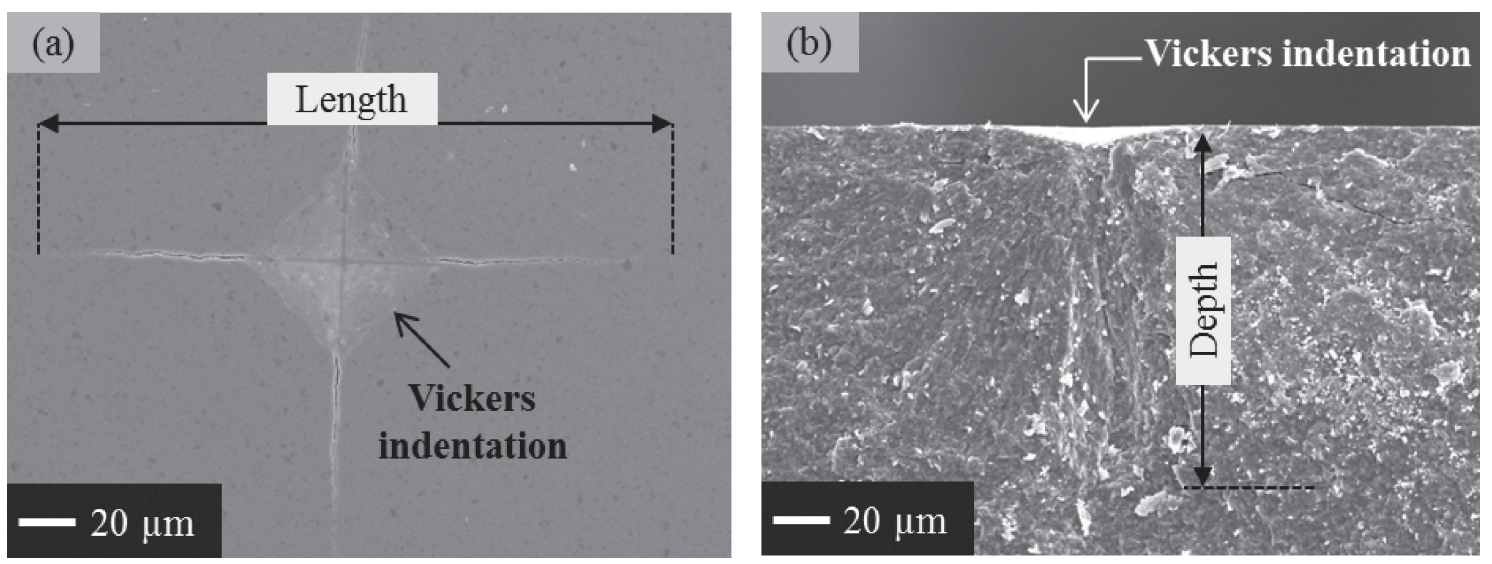

Fig. 2 SEM images show (a) crack on sample surface and (b) fracture surface of crack. 


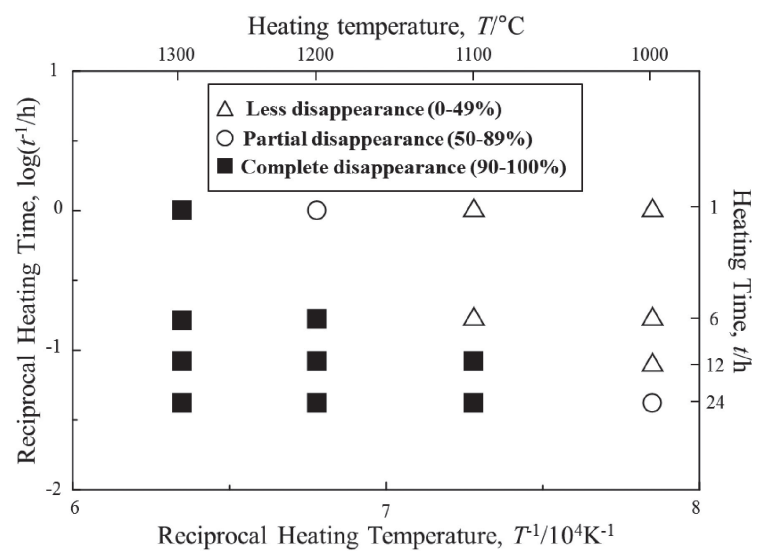

Fig. 4 Dependence of crack disappearance on reciprocal time and temperature.

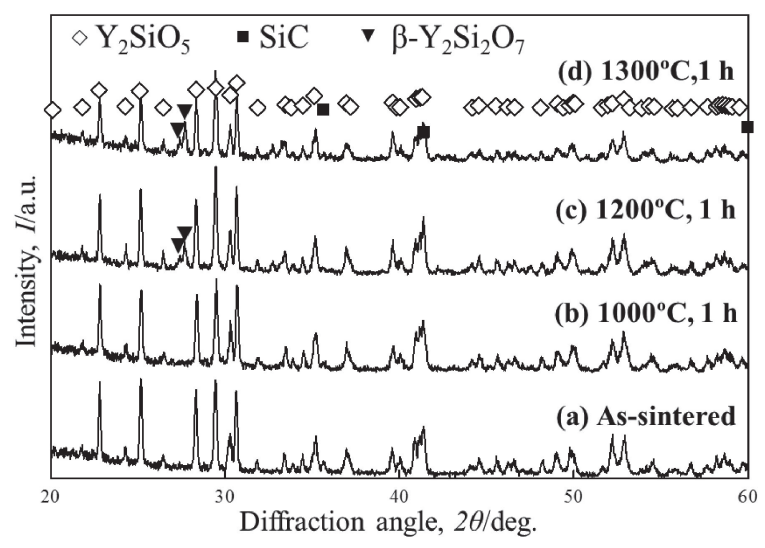

Fig. 5 XRD pattern of sample surface before and after oxidation.

and (d). The comparison of Figs. 5(a), (c) and (d) indicates that peaks of oxidation product were detected on the surface of as-healed samples. Intensities of these new peaks became greater with higher heat treatment temperatures. A comparison between the XRD patterns of as-healed samples and the standard patterns indicated that the oxidation product was identified to be $\beta-\mathrm{Y}_{2} \mathrm{Si}_{2} \mathrm{O}_{7}$. The results mean that $\mathrm{SiC}$ particles were reacted with oxygen and $\mathrm{Y}_{2} \mathrm{SiO}_{5}$ matrix as the following equilibrium:

$$
\mathrm{SiC}+\mathrm{Y}_{2} \mathrm{SiO}_{5}+2 \mathrm{O}_{2}=\mathrm{Y}_{2} \mathrm{Si}_{2} \mathrm{O}_{7}+\mathrm{CO}_{2}(\mathrm{~g})
$$

Figure 6 shows bending strength of as-sintered, as-cracked and as-healed samples at room temperature. Bending strength of samples without surface cracks was approximately $280 \mathrm{MPa}$. After three-Vickers indentations were introduced on sample surface, cracking decreased the bending strength to approximately $100 \mathrm{MPa}$. By heat treatment at $1300^{\circ} \mathrm{C}$ for $1 \mathrm{~h}$ in air, bending strength of samples with introduced surface cracks was recovered up to $330 \mathrm{MPa}$.

\section{Discussion}

To clarify crack-healing ability of $5 \mathrm{SiC} / \mathrm{Y}_{2} \mathrm{SiO}_{5}$ composites, crack-disappearance performance of the composites should be compared with those of other composites. In case of $\mathrm{SiC} /$ mullite, $^{11}$ ) the surface cracks on surface of $20 \mathrm{SiC} /$ mullite samples were completely healed after heat treatment

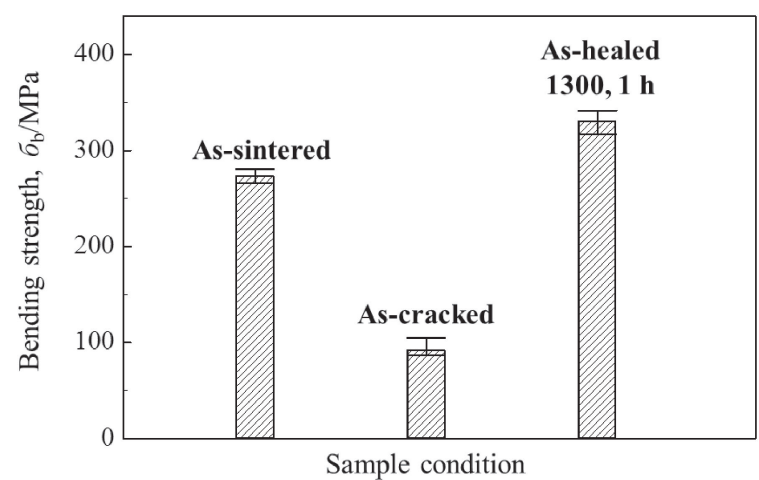

Fig. 6 Bending strength of as-sintered, as-cracked and as-healed samples at room temperature.

at $1300^{\circ} \mathrm{C}$ for $1 \mathrm{~h}$ in air. The crack-disappearance performance of this composite and $5 \mathrm{SiC} / \mathrm{Y}_{2} \mathrm{SiO}_{5}$ could be comparable. However, 20 vol\% $\mathrm{SiC}$ particles, much larger than 5 vol\% $\mathrm{SiC}$ dispersed in $\mathrm{SiC} / \mathrm{Y}_{2} \mathrm{SiO}_{5}$ composites, were dispersed in mullite matrix to cause complete healing of surface cracks. Because crack-healing of $\mathrm{SiC} /$ mullite composites was reported to be caused by formation of oxidation product, $\mathrm{SiO}_{2}$, associated with a volume expansion. More SiC particles on surface of crack are necessary to generate much $\mathrm{SiO}_{2}$ phase which accompanies the volume expansion induced crack-healing of $\mathrm{SiC} /$ mullite composites. On the other hand, in case of $\mathrm{Ni} / \mathrm{Al}_{2} \mathrm{O}_{3}$ composites, ${ }^{22)}$ crackhealing effectiveness of this composite could be also comparable to that of $5 \mathrm{SiC} / \mathrm{Y}_{2} \mathrm{SiO}_{5}$ at $1300^{\circ} \mathrm{C}$. Surface cracks could be healed completely with only 5 vol\% $\mathrm{Ni}$ particles dispersed in alumina matrix. Because of outward diffusion of $\mathrm{Ni}$ cations during oxidation process, there are a lot of $\mathrm{Ni}$ cations on surface of cracks to react with oxygen and the matrix which generates a top surface layer. The formation of the top surface layer caused the closure of surface cracks.

In order to clearly understand the difference in crackdisappearance performance of those ceramic matrix composites, their crack disappearance mechanism should be discussed. Two different self-healing mechanisms have been proposed in ceramic matrix composites. One is caused by volume expansion of dispersion located on the crack surface via high-temperature oxidation. Another one is caused by outward diffusion of cations during high-temperature oxidation. In $\mathrm{SiC} /$ ceramic systems such $\mathrm{SiC} / \mathrm{Al}_{2} \mathrm{O}_{3}$ and $\mathrm{SiC} /$ mullite with relatively large volume fraction of $\mathrm{SiC}$ dispersion, oxidation of $\mathrm{SiC}$ particles at high temperatures induced the formation of the oxidation product, $\mathrm{SiO}_{2}$, accompanies a volume expansion. ${ }^{10}$ Because of high value of the Pilling-Bedworth ratio in $\mathrm{SiC}(\approx 2.0)$, this oxidation process generates two times in volume expansion. $\mathrm{SiC}$ dispersion exposed on the crack surface was oxidized into $\mathrm{SiO}_{2}$ with volume expansion. In order to fill up the volume of surface cracks, large amount of $\mathrm{SiC}$ dispersion would be necessary. In case of $\mathrm{Ni} / \mathrm{Al}_{2} \mathrm{O}_{3}$ composites, this composite possess a greater crack-healing ability thanks to the faster diffusion of nickel cations in alumina matrix. ${ }^{24,25)}$ Oxidation of $\mathrm{Ni}$ particles at high temperatures, forming $\mathrm{NiAl}_{2} \mathrm{O}_{4}$ oxidation product, causes the outward diffusion of nickel cations along grain boundaries of $\mathrm{Al}_{2} \mathrm{O}_{3}$ matrix to the top 

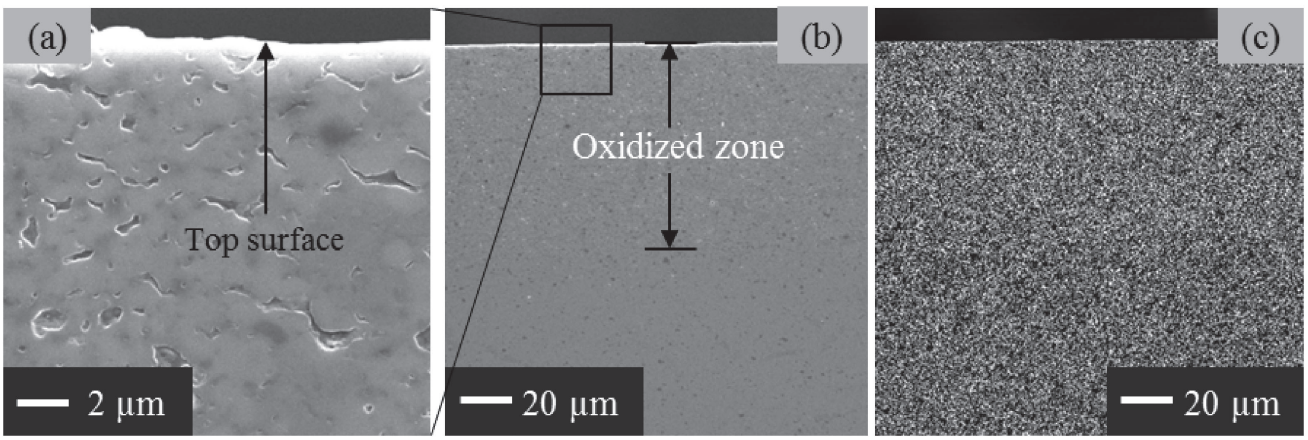

Fig. 7 SEM image of (a) oxidized zone and phase mapping at (b) cross-section surface for (c) $\mathrm{Si}$ of $\mathrm{SiC} / \mathrm{Y}_{2} \mathrm{SiO} 5$ sample oxidized at $1300^{\circ} \mathrm{C}$ for $6 \mathrm{~h}$.

surface. The outward diffusion results in formation of top surface layer. Thickness of the top surface layer is responsible for disappearance of surface cracks.

In terms of $\mathrm{SiC} / \mathrm{Y}_{2} \mathrm{SiO}_{5}$ composites, inward diffusion of oxygen passing through the component causes the oxidation of $\mathrm{SiC}$ particles within $\mathrm{Y}_{2} \mathrm{SiO}_{5}$ matrix to form $\mathrm{Y}_{2} \mathrm{Si}_{2} \mathrm{O}_{7}$ phase. This process induced a small volume expansion of 1.14 times. However, the small volume expansion could be not attributed to healing surface cracks. Because only 5 vol\% SiC on the sample surface (including crack surface) was not enough to create the oxidation product filling in the cracks. The surface cracks were healed by filling and re-bonding with $\mathrm{Y}_{2} \mathrm{Si}_{2} \mathrm{O}_{7}$ layer. The formation of $\mathrm{Y}_{2} \mathrm{Si}_{2} \mathrm{O}_{7}$ layer on the initial surface is proposed by outward diffusion of cations. The formation of sub-micron voids inside the sample after oxidation is the evidence of outward diffusion of cations, as shown in Fig. 7(a). The volume expansion of the dispersion could be compensated due to the formation of voids in the inside. However, interior cracks could be also generated because of volume expansion of the dispersion. This issue depends on diffusion coefficients of oxygen and cations in $\mathrm{Y}_{2} \mathrm{SiO}_{5}$ matrix. Until now, no data on diffusion coefficients of cations in $\mathrm{Y}_{2} \mathrm{SiO}_{5}$ ceramic was reported. The diffusivity of cations in $\mathrm{Y}_{2} \mathrm{SiO}_{5}$ ceramic will be studied further in order to clarify this matter. Si mapping at cross-sectional surface of $\mathrm{SiC} / \mathrm{Y}_{2} \mathrm{SiO}_{5}$ sample after heat treatment at $1300^{\circ} \mathrm{C}$ for $6 \mathrm{~h}$ in air was shown in Fig. 7(c). The difference in concentration of Si-phase at top surface, oxidized zone and non-oxidized zone could not be obviously distinguished. This fact seems to indicate that the outward diffusion of Si cations is not the dominant factor which causes the formation of $\mathrm{Y}_{2} \mathrm{Si}_{2} \mathrm{O}_{7}$ layer. Thus, the proposed mechanism of crack-healing for $\mathrm{SiC} / \mathrm{Y}_{2} \mathrm{SiO}_{5}$ composites is shown in Fig. 8. At elevated temperatures, oxygen can diffuse into the inside of the sample. $\mathrm{Y}^{3+}$ cations migrate outward, resulting in formation of $\mathrm{Y}_{2} \mathrm{Si}_{2} \mathrm{O}_{7}$ layer on the sample surface.

Nguyen et ll. $^{21)}$ mentioned that the mechanism of crackhealing in $\mathrm{SiC} / \mathrm{Yb}_{2} \mathrm{SiO}_{5}-\mathrm{Yb}_{2} \mathrm{Si}_{2} \mathrm{O}_{7}$ composites is the volume expansion of newly formed $\mathrm{Yb}_{2} \mathrm{Si}_{2} \mathrm{O}_{7}$ phase. The outward diffusion of cations leading the formation of oxidation product on the surface was not mentioned. A large fraction of $\mathrm{SiC}$ dispersoid is needed to cause effective disappearance of the cracks. A lot of interior cracks in the matrix would appear near the surface after heat treatment as well. Therefore, the outward diffusion of cations plays the major (a)

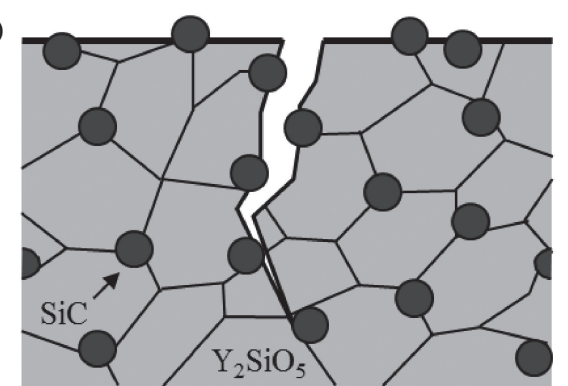

(b)
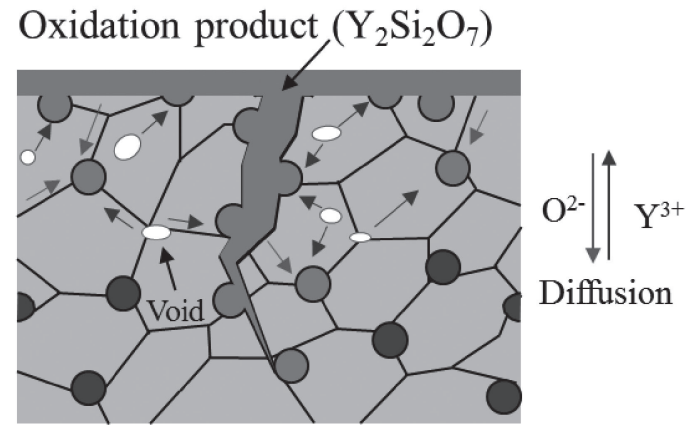

Fig. 8 Crack disappearance mechanism of $\mathrm{SiC} / \mathrm{Y}_{2} \mathrm{SiO}_{5}$ composites (a) after cracking and (b) during temperature increasing and healing.

role in self-healing performance of yttrium and ytterbium silicate composites dispersed with $\mathrm{SiC}$ particles.

Figure 9 shows SEM images observed on surface of bending test samples. Fracture mechanism of as-cracked sample was shown as Fig. 9(a). The Vickers indentation outlined by dash lines indicates that as-cracked sample fractured along surface cracks introduced by the Vickers indentation during bending test. After heat treatment at $1300^{\circ} \mathrm{C}$ for $1 \mathrm{~h}$ in air, oxidation products completely filled in surface cracks induced by the Vickers indentation. Figure 9(b) showed fracture mechanism of as-healed sample was different from that of as-cracked sample. The failure of as-healed sample did not occur along the Vickers indentation. This fact indicated that fracture strength at cracked region was recovered up to the same level of the region without cracks.

Figure 10 plots relationship between fraction of crack disappearance and bending strength. The bending strength of as-cracked sample was significant decreased by the introduced surface cracks. When fraction of crack disappear- 

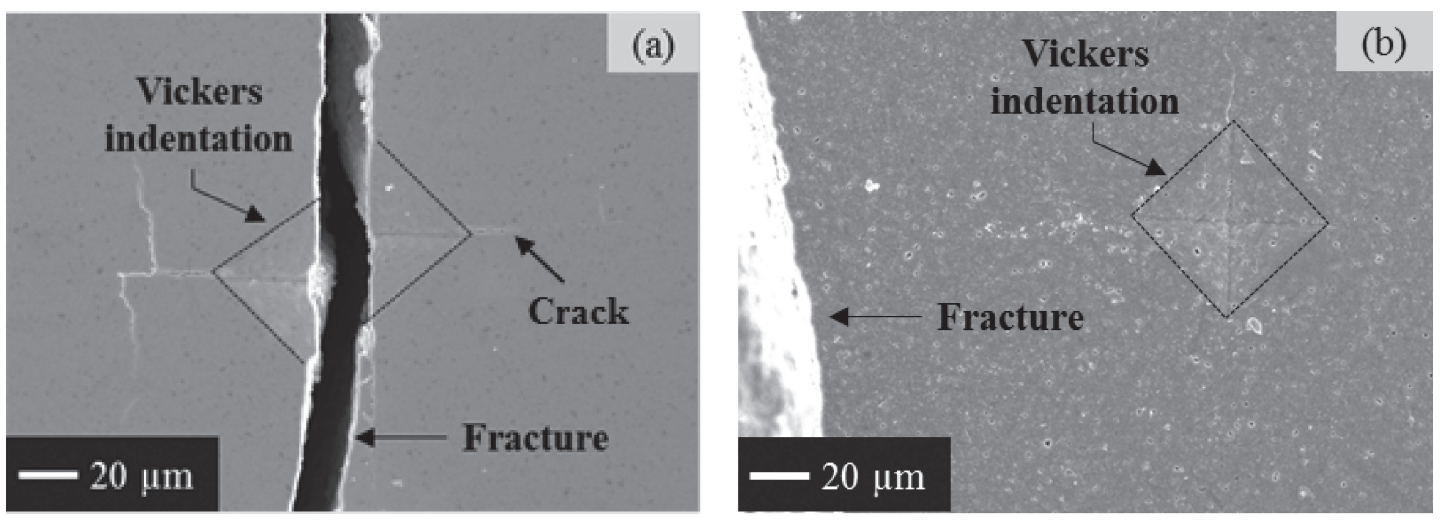

Fig. 9 SEM images show surface of bended samples (a) as-cracked and (b) as-healed at $1300^{\circ} \mathrm{C}$ for $1 \mathrm{~h}$ in air.

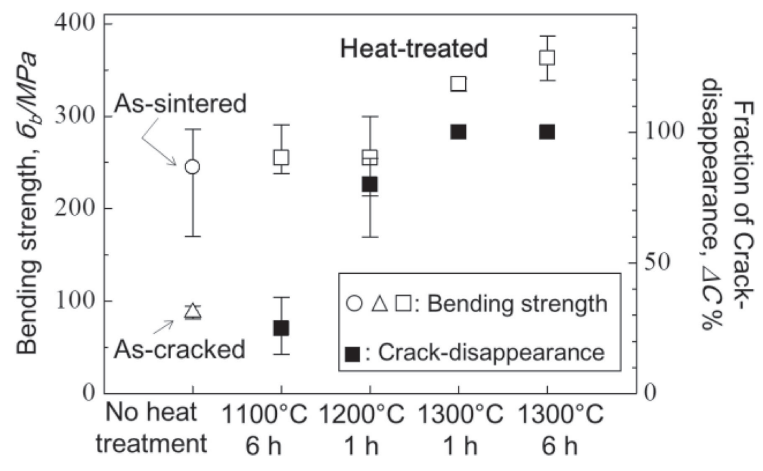

Fig. 10 Relationship between fraction of crack disappearance and bending strength of the samples heat-treated at various condition.

ance was approximately $25 \%$ after heat treatment at $1100^{\circ} \mathrm{C}$ for $6 \mathrm{~h}$, the bending strength increased to level as high as that of as-sintered sample. The fraction of crack disappearance increased up to $80 \%$ at $1200^{\circ} \mathrm{C}$ for $1 \mathrm{~h}$ and the bending strength remained comparable with that of as-sintered sample. The bending strength was a little higher than that of as-sintered sample when surface cracks were disappeared completely. Brittle materials, such as ceramics, typically fracture from the largest defect causing largest stress concentration. When the cracks were just disappeared partially, mechanical recovery could occur because remaining cracks were smaller than intrinsic defects. As shown in Fig. 2(b), the median crack propagating from the surface to inside of the sample had approximately $100 \mu \mathrm{m}$ in length. After heat treatment at $1100^{\circ} \mathrm{C}$ for $1 \mathrm{~h}$, length of the remaining crack had approximately $75 \mu \mathrm{m}$. On the other hand, the size of intrinsic defects was calculated through following equation:

$$
K_{\mathrm{IC}}=\sigma_{\mathrm{b}} \sqrt{\pi c}
$$

where $K_{\mathrm{IC}}$ is fracture toughness, $\sigma_{\mathrm{b}}$ is flexural strength and $c$ is size of defect. The average value of fracture toughness of $\mathrm{SiC} / \mathrm{Y}_{2} \mathrm{SiO}_{5}$ composites is estimated to be $3.3 \mathrm{MPam}^{1 / 2}$. Detail of the fracture toughness calculation has been reported by Sakai and Bradt. ${ }^{26}$ A comparison with mechanical properties of monolithic $\mathrm{Y}_{2} \mathrm{SiO}_{5}$, reported by Sun, $\left.{ }^{27}\right)$ indicated that dispersion of $\mathrm{SiC}$ particles in $\mathrm{Y}_{2} \mathrm{SiO}_{5}$ contribute to improve the fracture toughness and strength of $\mathrm{Y}_{2} \mathrm{SiO}_{5}$. Based on the eq. (2) and the values of $K_{\mathrm{IC}}$ and $\sigma_{\mathrm{b}}$, the average value of size of intrinsic defects is calculated to be approximately $80 \mu \mathrm{m}$. Because size of the remaining cracks is smaller than that of intrinsic defects, mechanical strength can be recovered completely. Formation of the oxidation product during heat treatment in air reduces stress concentration around the crack tips and leads to recovery of mechanical strength.

\section{Conclusions}

The ceramic matrix composites of $\mathrm{Y}_{2} \mathrm{SiO}_{5}$ with 5 vol\% $\mathrm{SiC}$ particles with self-healing effectiveness can be successfully fabricated by the pulsed electric current sintering technique. $\mathrm{SiC} / \mathrm{Y}_{2} \mathrm{SiO}_{5}$ composites exhibited a considerable crackhealing ability induced by high-temperature oxidation process. Introduced cracks with $200 \mu \mathrm{m}$ in length on surface sample was disappeared completely after heat treatment at $1300^{\circ} \mathrm{C}$ for $1 \mathrm{~h}$ in air. Surface cracks were filled up by the oxidation product of $\beta-\mathrm{Y}_{2} \mathrm{Si}_{2} \mathrm{O}_{7}$ generated by reaction of $\mathrm{SiC}$ dispersion with oxygen and $\mathrm{Y}_{2} \mathrm{SiO}_{5}$ matrix. The formation of $\mathrm{Y}_{2} \mathrm{Si}_{2} \mathrm{O}_{7}$ was considered as outward diffusion of $\mathrm{Y}^{3+}$ cations. Bending strength of crack-disappeared sample was recovered up to approximately $330 \mathrm{MPa}$ which was comparable with that of as-sintered sample.

\section{Acknowledgments}

The authors wish to express their gratitude to the Japan Science and Technology Agency for supporting partially this study through the Advanced Low Carbon Technology Research and Development Program.

\section{REFERENCES}

1) J.B. Min, D.L. Harris and J.M. Ting: 52nd AIAA/ASME/ASCE/ AHS/ASC Structures, Structural Dynamics and Materials Conference 19th, 4-7 April 2011, Denver, Colorado.

2) N.S. Jacobson: J. Am. Ceram. Soc. 76 (1993) 3-28.

3) N.S. Jacobson, E.J. Opila and K.N. Lee: Curr. Opin. Solid State Mater. Sci. 5 (2001) 301-309.

4) J.R. Price, M. van Roode and C. Stala: Key Eng. Mater. 72-74 (1992) 71-84.

5) K.N. Lee, R.A. Miller and N.S. Jacobson: J. Am. Ceram. Soc. 78 (1995) 705-710.

6) K.N. Lee: Trans. ASME 122 (2000) 632-636.

7) J. Kimmel, N. Miriyala, J. Price, K. More, P. Tortorelli and H. Eaton: 
J. Eur. Ceram. Soc. 22 (2002) 2769-2775.

8) K.N. Lee, D.S. Fox, J.I. Eldridge, D. Zhu, R.C. Robinson and N.P. Bansal: J. Am. Ceram. Soc. 86 (2003) 1299-1306.

9) K.N. Lee, D.S. Fox and N.P. Bansal: J. Eur. Ceram. Soc. 25 (2005) 1705-1715.

10) M.C. Chu, S. Sato, Y. Kobayashi and K. Ando: Fatigue Fract. Eng Mater. Struct. 18 (1995) 1019-1029.

11) K. Ando, M.C. Chu, K. Tsuji, T. Hirasawa, S. Kobayashi and S. Sato: J. Eur. Ceram. Soc. 22 (2002) 1313-1319.

12) K. Takahashi, M. Yokouchi, S.K. Lee and K. Ando: J. Am. Ceram. Soc. 86 (2003) 2143-2147.

13) Z. Derelioglu, A.L. Carabat, G.M. Song, S. van der Zwaag and W.G. Sloof: J. Eur. Ceram. Soc. 35 (2015) 4507-4511.

14) F. Nozahic, D. Monceau and C. Estournès: Mater. Des. 94 (2016) 444 448

15) S.-H. Jeon, S.-H. Jung and Y.-G. Jung: J. Kor. Ceram. Soc. 54 (2017) $492-498$
16) T. Ouyang, J. Wu, M. Yasir, T. Zhou, X. Fang, Y. Wang, D. Liu and J. Suo: J. Alloys Compd. 656 (2016) 992-1003.

17) N.P. Padture, M. Gell and E.H. Jordan: Science 296 (2002) 280-284.

18) J.D. Osorio, A. Toro and J.P. Hernandez-Ortiz: Dyna (Bilbao) 79 (2012) 149-158.

19) L.B. Chen: Surf. Rev. Lett. 13 (2006) 535-544.

20) H. Dinh Vu and M. Nanko: Key Eng. Mater. 728 (2017) 149-154.

21) S.T. Nguyen, T. Nakayama, H. Suematsu, T. Suzuki, L. He, H.B. Cho and K. Niihara: J. Am. Ceram. Soc. 100 (2017) 3122-3131.

22) D. Maruoka and M. Nanko: Mater. Sci. Forum 696 (2011) 378-383.

23) D. Maruoka and M. Nanko: Ceram. Int. 39 (2013) 3221-3229.

24) M. Nanko: Sci. Technol. Adv. Mater. 6 (2005) 129-134.

25) A.L. Salas-Villaseñor, J. Lemus-Reiz, M. Nanko and D. Maruoka: Adv. Mater. Res. 68 (2009) 34-43.

26) M. Sakai and R.C. Bradt: Int. Mater. Rev. 38 (1993) 53-78.

27) Z. Sun, J. Wang, M. Li and Y. Zhou: J. Eur. Ceram. Soc. 28 (2008) 2895-2901. 